Key Sandy Caro Mejía

ISSN 2145-6054

e-ISSN 2256-2796

\title{
“HERMENÉUTICA JUDICIAL PARA LA PROTECCIÓN DE LOS SEGUNDOS OCUPANTES EN EL PROCESO DE RESTITUCIÓN Y FORMALIZACIÓN DE
} TIERRAS"

"Judicial hermeneutics for the protection of second occupants in the process of restitution and formalization of lands"

Key Sandy Caro Mejía ${ }^{59}$

Fecha de recepción: 10 de octubre de 2017

Fecha de aceptación: 30 de noviembre de 2017

SUMARIO: 1. Introducción; 2. El proceso de restitución de tierras y la figura jurídica de la oposición como garantía de los terceros afectados; 3. Marco jurídico aplicable a los afectados con la orden de restitución; 4. Criterios orientadores o reglas hermenéuticas para el análisis diferenciado la conducta de los sujetos afectados con la orden de restitución y formalización de tierras; 5. Herramienta metodológica de interpretación para la aplicación diferencial del estándar de la buena fe exenta de culpa; 6. Conclusión; 7. Bibliografía

\footnotetext{
${ }^{59}$ Abogada egresada de la Universidad Libre, con distinción por su rendimiento académico y resultados obtenidos en las pruebas de conocimiento aplicadas por el Estado, conforme resoluciones 022 y 026 del 26 de mayo 2011. Especialista en derecho procesal de la Universidad Libre y Magister en derecho con profundización en constitucionalismo y sociedad de la Universidad de Cartagena. Servidora pública de la Rama Judicial en la especialidad civil especializada en Restitución de Tierras. https://orcid.org/0000-0003-3014-7006 E-Mail: key sandyc@hotmail.com
} 


\section{COMO SE CITA ESTE ARTíCULO (APA 6)}

Caro Mejía, Key Sandy (2018). Hermenéutica judicial para la protección de los segundos ocupantes en el proceso de restitución y formalización de tierras. Revista Jurídica Mario Alario D’Filippo, Vol. X, Nº19, pág. 250 - 270

\section{RESUMEN}

El presente artículo aborda las exigencias de carácter normativo y factico prescritas por la Ley 1448 de 2011, para analizar la figura jurídica de la oposición, presentada por quienes pretendan hacer valer los derechos adquiridos posteriormente sobre los predios que se reclaman en dicho proceso y la correlativa exigencia de probar un comportamiento ajustado al estándar de la buena fe exenta de culpa como presupuesto para obtener una compensación económica; en contraste a una realidad de déficit de protección a ocupantes secundarios vulnerables y legítimos, que no han superado dicho parámetro planteando por la ley, frente a quienes la sentencia constituye una lesión inaceptable a mandatos constitucionales que les protegen. Frente a esta realidad inicialmente no prevista por la Ley, ha sido la jurisprudencia del máximo Tribunal Constitucional que, en consideración a los derechos de los afectados con la orden de restitución, ha planteado criterios orientadores de hermenéutica judicial, los que acompañados del método argumentativo que en el presente artículo se plantea, conducirán a justificar la decisión que al respecto se adopte.

\section{Palabras Claves}

Proceso de restitución y formalización de tierras, opositor, buena fe exenta de culpa, compensación, segundos ocupantes, derecho a la vivienda y el patrimonio, ponderación.

\section{ABSTRACT}

This essay concerns the legal and factual conditions prescribed by Statute $n$. 1448/2011, in order to analyze the legal institute of the "opposition", employed by those who want to safeguard their vested rights on the lands which are claimed within that trial, and the connected burden of proof relating to the circumstance of having behaved in accordance with the so called "good faith without fault/negligence", which is a fundamental requirement to obtain an economic compensation; in contrast with a situation of lack of protection suffered by vulnerable and rightful successive occupiers, who have not satisfied that condition set forth by the mentioned Statute, with respect to whom the sentence represents an unacceptable infringement of their constitutional rights. Faced with this situation, the case law of the Supreme Constitutional Tribunal, considering the rights broken through de restitution order, has established interpretative criteria for the judges which, together with the argumentative pattern described in this essay, will contribute to legitimate the judicial decisions.

\section{Key Words}

Process of restitution and formalization of lands, opponent, good faith without fault, compensation, second occupants, right to housing and heritage, ponderation. 


\section{INTRODUCCIÓN}

El presente artículo es el resultado de una investigación jurídica en la que se examinaran las exigencias de carácter normativo prescritas en la regulación del proceso de restitución y/o formalización de tierras, Ley 1448 de 2011. Se analizarán en esta medida las consideraciones jurídicas y fácticas para aquellas personas que, afectadas con la orden de restitución y consecuente desalojo del predio objeto de solicitud, pretenden hacerse a la compensación económica prescrita por esta ley, y equivalentes consideraciones para quienes se presentan a dicho proceso por verse afectado su derecho o situación jurídica protegida por la ley, en relación directa con el bien a restituir.

De esta forma, se analiza la figura jurídica de la oposición dentro del referido proceso, haciendo un contraste frente a la realidad de un déficit de protección del sujeto que pretende acceder a los beneficios prescritos por la ley. Quienes, por tanto, se presentan a la actuación judicial a fin de obtener el reconocimiento de una compensación económica en su favor, y/o medidas afirmativas que garanticen la protección de sus derechos a la vivienda digna y/o patrimonio asociado a la subsistencia mínima.

Claro es que el amparo del derecho a la restitución pretendido con la acción de restitución y/o formalización de tierras, persigue la reivindicación del derecho que le asiste al trabajador rural a vincularse formalmente a la tierra en la cual, previo al desplazamiento, desarrollaba su proyecto de vida familiar y patrimonial, ello acompañado de todas las garantías de estabilización socio económicas necesarias para tal fin (artículo 67, Ley 1448 de 2011). Sin embargo, la redacción de la Ley, parece no tomar en cuenta la realidad de quienes se oponen o simplemente se afectan con dicha orden de restitución, pues muchas veces comparten similares condiciones de vulnerabilidad con la parte solicitante, y en ocasiones, receptores incluso también del flagelo del conflicto armado interno.

Pese a este escenario fáctico y jurídico no previsto en la norma, el operador judicial deberá, cumplir su deber ontológicamente asignado, de producir un fallo definitivo en ocasión de la Litis que responda al orden constitucional y a la finalidad misma del proceso; razón por la cual el presente trabajo pretende responder mediante el estudio de información de carácter secundario usando el método analítico descriptivo con un enfoque cualitativo la siguiente pregunta problema ¿Cuál es la herramienta metodología de interpretación que, consultando la finalidad del proceso de restitución y formalización de tierras, permite justificar la decisión judicial en cuanto al reconocimiento de medidas compensatorias a los ocupantes secundarios legítimos y vulnerables? 
Key Sandy Caro Mejía

\section{El proceso de restitución de tierras y la figura jurídica de la oposición como garantía de los terceros afectados}

En el marco de una política estatal encaminada a contrarrestar los efectos del fenómeno del desplazamiento forzoso en Colombia, realidad puesta en evidencia en el Documento CONPES 2804 de 1995, el cual es objeto de regulación a través de la Ley 387 de 1997, se expiden una multiplicidad de normas que comienzan a regular la materia como nunca antes en la historia del país. En este escenario se destacan el CONPES 3057 de 1999 y los Decretos 173 de 1998, 2569 de 2000 y 951 de 2001 . Todo este compendio normativo está encaminado a suplir dos necesidades básicas: La primera, brindar una respuesta institucional a la problemática nacional que acarreó la configuración de tal flagelo. La segunda, cumplir los mandatos constitucionales y legales de protección a la población victimizada.

El alcance de la restitución de tierras está supeditado a la capacidad que tiene el Estado de resolver, por cuenta de dicha etapa, la problemática estructural de la reforma agraria, como se dijo: epicentro del conflicto en Colombia. (Gutiérrez, 2014. p. 160)

Tales obligaciones, especialmente las referidas al reconocimiento de unos contenidos mínimos o esenciales de satisfacción de los derechos de los sujetos pasivos de migración, vienen expresamente impuestas al Estado Colombiano por la H. Corte Constitucional en el año 2004, cuando previno la necesidad de adoptar los correctivos necesarios para asegurar que el nivel de protección definido por el Legislador y desarrollado por el Ejecutivo, fuese efectivamente alcanzado. Tal emblemático pronunciamiento, vertido en la Sentencia T - 025 de 2004, se cimienta en el reconocimiento de la configuración del desplazamiento forzado interno en Colombia de grandes masas poblacionales, situándolo como una dinámica actual que tuvo su inicio en la década de los años ochenta, como resultado del conflicto armado interno; examen que desemboca en la declaratoria del estado de cosas inconstitucionales a la población víctima de dicho fenómeno.

Ante lo expuesto por la H. Corte Constitucional en su Sentencia, el Estado Colombiano realiza una serie de esfuerzos institucionales encaminados a revestir de garantías a dicho grupo poblacional, teniendo como principales propósitos la procura de la satisfacción de sus derechos a la verdad, justicia y reparación, como los cauces que conducen a la paz duradera y sostenible, así como también la reconciliación nacional, que persigue el proceso transicional que atraviesa el país.

En este contexto, como una de las respuestas asociadas al componente de la reparación, se inicia un proceso que comprende, entre otras medidas, la restitución de tierras. Se expide entonces la Ley 1448 de 2011, también Ilamada Ley de Víctimas, con sus respectivos decretos reglamentarios. Este compendio normativo busca concretizar la garantía de las víctimas a demandar la efectividad 
del amparo de la restitutio in integrum, figura esta entendida como el restablecimiento de la situación anterior a las violaciones contempladas en el artículo $3^{\circ}$ de la presente Ley (artículo 71), mediante mecanismos judiciales y no judiciales, destacando entre éstos, el proceso especial y constitucional denominado acción de restitución y/o formalización de tierras.

Tal proceso judicial responde al compromiso asumido por el Estado, conforme quedó consignado en la exposición de motivos de la antes citada Ley, en cuanto busca "...lograr un amparo integral de las víctimas, que abarque mecanismos de asistencia, atención, prevención, protección, reparación integral con enfoque diferencial, acceso a la justicia y conocimiento de la verdad, ofreciendo herramientas para que aquellas reivindiquen su dignidad y desarrollen su modelo de vida; anotando que, sólo con la materialización de este objetivo es posible lograr la finalidad última de la justicia transicional en Colombia, como recuperación de los traumas de violencia sistemática y generalizada: La reconciliación nacional..." (Ley 1448 de 2011).

El amparo del derecho a la restitución pretendido con este tipo de acción, persigue la reivindicación del derecho que le asiste al trabajador rural a vincularse formalmente a la tierra en la cual, previo a que sucediese el desplazamiento, desarrollaba su proyecto de vida familiar y patrimonial; ello acompañado de todas las garantías de estabilización socio - económicas necesarias para tal fin (artículo 67, Ley 1448 de 2011). Para poder materializar tales derechos y protección, la Ley de Víctimas prevé la posibilidad de reputar la inexistencia y/o declarar la anulación de los actos o negocios posteriores que se hubieren celebrado, bien sea sobre la totalidad, o sobre una parte del bien inmueble, que sería entregado a quien es declarado víctima cualificada de abandono forzoso y/o despojo del fundo (artículos 77, 91, y concordantes de la Ley 1448 de 2011), y reclama los derechos sobre esa tierra; conduciendo en últimas, al restablecimiento de su relación con la tierra, en aplicación del principio de justicia restaurativa.

El escenario que se describe con la acción de restitución apareja consecuente la pérdida o cesación de la relación material o jurídica de quien hasta entonces se encontraba vinculado al predio a restituir. La persona afectada por la reclamación sobre la tierra deberá restablecer la situación fáctica y jurídica en beneficio de quien fue declarado víctima de desplazamiento forzoso producto del conflicto armado interno; para aquel, el proceso propuesto por la Ley 1148 de 2011 le confiere el derecho a intervenir bajo la figura procesal de la oposición.

La oposición apareja una gran rigurosidad en cuanto a la actividad probatoria, así como respecto del análisis de la conducta con la cual consolidó la referida relación material o jurídica con el inmueble pretendido; imponiéndole entre otras, la carga de probar el nacimiento de su relación con el predio en discusión, bajo un estándar calificado el principio de buena fe, denominado exenta de culpa, ello a fin de obtener una compensación económica, conforme lo preceptúa los artículos 88,91 y 98 , entre otros de la norma en cita. 
Frente a dicha exigencia, por interpretación judicial se han propuesto fórmulas tales como la aplicación del test de proporcionalidad o razonabilidad a fin de degradar el estudio de la buena fe exenta de culpa a buena fe simple (Ramírez, 2013, pág. 75); y, a su turno, el estado de necesidad, por razones de equidad frente a terceros en iguales o mayores condiciones de vulnerabilidad que las propias víctimas reclamantes (Vargas, 2013, págs. 83-84).

En relación a la señalada afectación de terceros con la orden de restitución de sus derechos a la vivienda digna y el patrimonio asociado a la subsistencia mínima, como una problemática surgida de escenarios de justicia transicional producto de contextos de conflicto armado interno, el Informe Preliminar y el Manuel sobre la Restitución de Viviendas y de Patrimonio con motivo del Regreso de los Refugiados y Desplazados Internos, conceptualizó sobre el fenómeno de ocupación secundaria, estableciendo un estándar internacional a aplicar, que es incorporado al ordenamiento interno a través del bloque de constitucionalidad en sentido lato $(\mathrm{H}$. Corte Constitucional, C - 821 de 2007, C - 715 de 2012, C - 281 de 2013) para la protección de sus derechos.

Al respecto de la ocupación segundaria la H. Corte Constitucional en Sentencia C - 330 de 2016, reconoció su existencia y el déficit de protección legal respecto del segmento vulnerable de ésta, en relación al cual se previene la necesidad de ser tenido en cuenta al momento de establecer políticas, normas y programas de restitución de tierra en escenarios de transición, como presupuesto para el éxito y la estabilidad de las medidas, y para la seguridad en los derechos reconocidos a las víctimas restituidas, especialmente, en lo que tiene que ver con la tenencia de la tierra, la vivienda y el patrimonio. Este fenómeno ocasiona, para el Máximo Tribunal Constitucional, tensiones de derechos que deben ser resueltas por el Juez de Restitución de Tierras, bajo una justificación que se acerque al modelo de decisión de los jueces constitucionales, requiriendo un intenso ejercicio argumentativo.

Toda la referida regulación del proceso busca como finalidad la armonización del amparo del derecho a la restitución, no sólo en cuanto al castigo y erradicación de actos o prácticas instrumentales al desplazamiento forzoso y al aprovechamiento de la situación de violencia respecto de quien se vinculó al predio con posterioridad a la migración forzada del que es declarado víctima, cuando las circunstancias así lo evidencien, sino también a través de la intervención afirmativa del Juez, cuando deban contrarrestarse los efectos de una aplicación genérica de la norma, en casos en los que se comprometan los derechos a la vivienda digna y patrimonio asociado a la subsistencia mínima de personas vulnerables o incluso ya víctimas; esto último, con el propósito de ajustar las decisiones tanto administrativas como judiciales al objetivo primordial del proceso, el cual es la consecución de reconciliación y paz duradera y estableartículo 9 de la Ley 1448 de 2011, en procura de mitigar el impacto social y económico que se 
cause de manera negativa a grupos poblacionales que a causa de sus condiciones personales, advierten debilidad relevante y manifiesta.

Parece existir brecha, a modo de ambigüedad normativa que no cierra la Ley, entre la severidad de consecuencias respecto del tercero vinculado al predio con posterioridad al desplazamiento del sujeto declarado víctima, y el sistema de respeto y garantías a los derechos individuales o mínimos prestacionales afectados con la orden de restitución. Esta situación debe sortearla el operador judicial, a quien le corresponde en cada caso en concreto, no solamente distinguirla, sino y sobre todo, superarla. Esta situación es la que enmarca el problema de investigación propuesto en el presente trabajo, encaminado a determinar ¿Cuál es la herramienta metodología de interpretación que, consultando la finalidad del proceso de restitución y formalización de tierras, permite justificar la decisión judicial en cuanto al reconocimiento de medidas compensatorias a los ocupantes secundarios legítimos y vulnerables?

El método hermenéutico para su desarrollo será el sistemático, a través de la técnica de integración normativa, mediante la cual se describirá el marco jurídico aplicable a los afectados con la orden de restitución emitida en razón del proceso previsto por la Ley 1448 de 2011, permitiendo distinguir entre la categoría conceptual de oposición y ocupación secundaria. Seguidamente, se sintetizarán los parámetros o criterios hermenéuticos dispuestos por la jurisprudencia para realizar un análisis diferenciado del estándar general de la buena fe exenta de culpa requerida para acceder a una compensación económica. Para a partir de lo anterior, determinar la herramienta metodología de interpretación de la que ha de valerse el operador judicial para justificar de forma sólida, coherente y consistente, su decisión en cuanto al reconocimiento de medida compensatoria en favor de ocupantes secundarios legítimos $y$ vulnerables.

3. Marco jurídico aplicable a los afectados con la orden de restitución: Aproximación a la distinción entre oposición y ocupación secundaria

La Ley 1448 de 2011 en su artículo 88 prescribe que, frente a la solicitud de restitución de tierras, se podrá presentar bajo la gravedad del juramento, oposición dentro de los quince (15) días siguiente a la notificación; se enuncian y se indican de esta manera las formas a partir de la cual se puede sustentar tal defensa:

1) la tacha de la calidad de despojado de la persona o grupo en cuyo favor se presentó la acción; 2) o simplemente el referido opositor hace valer como prueba

a) su calidad de despojado del respectivo predio,

b) haber obrado bajo los cánones de la buena fe exenta de culpa,

c) ostentar justo título de su derecho; dejando abierto otros medios exceptivos y probatorios que considere pertinentes. 
De la norma citada se deriva la distinción de dos tipos de opositores, uno de ellos colocado en un plano de igualdad frente al solicitante del amparo del derecho a la restitución, pues predica su victimización como despojado del mismo predio (artículos 78, 88 y 97 literal b); y el otro con la capacidad de exhibir un justo título, de acreditar la existencia de buena fe exenta de culpa, entre otras formas no dispuestas expresamente en la norma, de lo que se deriva el carácter enunciativo de tal disposición. Al respecto del reconocimiento al opositor de la condición de víctima de abandono forzoso y/o despojo, la Ley 1448 de 2011 en el literal b del artículo 97 y el artículo 78, lo reduce a que se trate del fenómeno de despojos sucesivos.

De esta forma tenemos que los opositores en la Ley 1448 de 2011, están distinguidos por dos categorías principalmente, los que se reconocen igualmente víctimas de despojo del mismo predio, y los que no ostentan tal calidad; para cada uno de los cuales, la norma previene una respuesta diferente, a saber:

A los opositores víctimas de despojo del mismo predio, dado el plano de igualdad frente a la parte solicitante, se les inaplica el principio procesal general de inversión de carga de prueba (art. 78) por expresa consagración legal, por lo que la Litis se resuelve bajo la subsunción de la situación fáctica en la premisa normativa del literal $b$ del artículo 97 de la Ley 1448 de 2011, que prescribe el reconocimiento de compensación atendiendo a la imposibilidad de restitución material fundamentada en que sobre el predio reclamado se presentaron despojos sucesivos, y que el bien fue restituido a otra víctima del mismo predio (art. 97, literal b), como sería en tal caso, el solicitante.

La compensación se podrá hacer con un predio de igual significancia medioambiental o económica, o con pago en efectivo por equivalencia económica, siguiendo el mismo orden de preferencia en cuanto a su reconocimiento, siempre conforme con lo dispuesto en el Decreto Reglamentario 4829 de 2011, artículo 38.

En este evento la norma no hace referencia a la aplicación del estándar de la buena fe exenta de culpa (art. 88), por cuando al opositor se le coloca en un plano de igualdad frente al solicitante, recibiendo ambos el tratamiento de víctimas, y con ello, la respuesta a éstos debe implicar el amparo del derecho a la restitución, cuya fórmula diseñada será la entrega material y jurídica del fundo reclamado a uno y, el reconocimiento de una compensación por equivalencia al otro.

En lo que concierte a los opositores que no ostentan la calidad de víctima del mismo predio, la Ley 1448 de 2011 procesalmente les impone la carga de la prueba del hecho que alegan o en el que fundamentan sus intereses jurídicos (artículo 78); uno de éstos su buena fe exenta de culpa, requerida para obtener el pago de compensación económica (art. 98). 
De esta forma, la prosperidad de una compensación en el marco de la Ley 1448 de 2011, se concreta con el reconocimiento para el afectado de la orden de restitución por haber obrado bajo el canon de la buena fe exenta de culpa, parámetro que no fue definido dentro del texto de la ley, por lo que los Jueces de Restitución, como operadores jurídicos, han recurrido a la Jurisprudencia de la Corte Suprema de Justicia y de la Corte Constitucional a fin de establecer el criterio de evaluación de la buena fe calificada, entendiéndola como "error invencible", asociando ello a que el opositor no hubiese podido conocer del contexto de violencia o de la presencia de grupos amados en el lugar donde se encontraba el predio; o cuando el opositor ha demostrado que no se ha valido del contexto de violencia para adquirir el inmueble; o que este sujeto no tiene relación directa o indirecta con grupos armados ilegales, o con la situación de conflicto armado que dio lugar al abandono o al despojo forzoso (Quinche, Peña, Parada, Ruíz, \& Álvarez, 2015).

Sobre el particular, el máximo Tribunal Constitucional en múltiples pronunciamientos, entre otros en la Sentencias C - 740 de 2003, C - 795 de 2015, reiterado en la C - 330 de 2016, dispone que la buena fe calificada se encuentra inspirada en una máxima legada del derecho antiguo: 'Error communis facit jus', referente a la situación en que una persona que cree adquirir un derecho, o colocarse en una situación jurídica protegida por la ley, sin embargo, dicho derecho o situación no existe en tanto ha cometido un error o equivocación, que una persona prudente o diligente no hubiese cometido.

Con lo anterior se define el elemento subjetivo del principio de buena fe de rango constitucional (artículo 83 C.P), valorado en el marco convencional, por la creencia o convicción de alguien de haber adquirido un derecho o colocarse en una situación jurídica protegida por la ley, como viene indicado. Sin embargo, para la justicia transicional, por la connotación de interés público, referido al esclarecimiento de la verdad para la víctima y la institucionalidad que pretende ser recuperada, el principio de buena fe se cualifica a través de la exigencia del elemento objetivo que comporta la necesidad de verificarse un actuar prudente y diligente que imprima certeza a que no se esté frente a un derecho o situación espuria en la que sea posible descubrir su falsedad o no existencia.

La H. Corte Constitucional en Sentencia C - 330 de 2016, lo denomina como un parámetro de probidad y una carga sustantiva referente a las actuaciones de las personas que llegaron, adquirieron u ocuparon un predio en el grave contexto de violación de derechos generado por el conflicto armado interno, donde el desplazamiento forzado, el despojo, la usurpación y abandono de predios, afectaron a gran parte de la población, especialmente, en las zonas rurales del país.

Tal presupuesto de sumo rigor sustancial nace de un supuesto del que parte la Ley de Víctimas, en la práctica muchas veces errático, en que los opositores son guerrilleros, paramilitares, narcotraficante o los testaferros de éstos, o quienes se aprovecharon del conflicto para hacerse a 
las tierras de los desplazados, a fin de castigar tales conductas. La realidad evidenciada en los procesos, planteó otro panorama, pues los casos que se han recibido tienen como opositores a campesinos y colindantes de los predios que están en reclamación (Ramírez, 2013, pág. 71).

De forma que, aun cuando la ley se encontraba prevista para opositores con medios suficientes para la defensa de sus derechos, a los procesos de restitución, están llegando opositores que alegan igual condición de víctima que la parte solicitante. Este fenómeno viene dado por la macro y micro focalización, a través de la cual se ha realizado una priorización temporal y territorial, teniendo en cuenta las condiciones de seguridad en los territorios, sin que se prevenga que están llegando casos de opositores víctimas y en condiciones similares de vulnerabilidad a las del actor (Vargas, 2013, pág. 78).

En tal contexto, el máximo Tribunal Constitucional, entre otros pronunciamientos, en Sentencias C - 330 de 2016, T - 315 de 2016, T - 367 de 2016, T - 529 de 2016 y auto de seguimiento 373 de 2016, reconoció que muchos de los opositores que acuden a los procesos de restitución no armonizan con la figura de opositores/presuntos victimarios que planteó la Ley de Victimas para tramitar la restitución, acudiendo como categoría sustancial para darle solución a la problemática de la población vulnerable que se afecta con la orden de restitución, al fenómeno de la ocupación secundaria, regulado en los Principios sobre la restitución de las viviendas y el patrimonio de los refugiados y las personas desplazadas (2005) de las Naciones Unidas, más conocidos como los "Principios Pinheiro", los cuales hacen parte de la doctrina iusinternacionalista denominada derecho blando o soft law (H. Corte Constitucional T - 300 y 315 de 2016), incorporados como viene expuesto al ordenamiento interno a través del bloque de constitucionalidad en sentido lato.

Los ocupantes secundarios por su parte, si bien no se encuentran definidos de forma específica en los Principios Pinheiro, en el Manual de aplicación de los mismos, publicado por la Oficina del Alto Comisionado de las Naciones Unidas para los Refugiados, se señala que:

\footnotetext{
"Se consideran ocupantes secundarios todas aquellas personas que hubieran establecido su residencia en viviendas o tierras abandonadas por sus propietarios legítimos a consecuencia de, entre otras cosas, el desplazamiento o el desalojamiento forzosos, la violencia o amenazas, o las catástrofes naturales, así como las causadas por el hombre".
}

Al respecto, el Informe Preliminar Restitución de Viviendas y de Patrimonio con motivo del regreso de los refugiados y desplazados internos publicado en el año dos mil tres (2003), señaló que no es un fenómeno estático, pues puede adoptar diferentes formas, cada una de las cuales demanda estrategias de atención específicas. En similar sentido, la $\mathrm{H}$. Corte Constitucional en Sentencia C - 330 de 2016 reconoció el carácter heterogéneo de tal población, al señalar que: 
"Los segundos ocupantes no son una población homogénea: Tienen tantos rostros, como fuentes diversas tiene la ocupación de los predios abandonados y despojados. A manera ilustrativa, puede tratarse de colonizadores en espera de una futura adjudicación; personas que celebraron negocios jurídicos con las víctimas (negocios que pueden ajustarse en mayor o menor medida a la normatividad legal y constitucional); población vulnerable que busca un hogar; víctimas de la violencia, de la pobreza o de los desastres naturales; familiares o amigos de despojadores; testaferros o 'prestafirmas' de oficio, que operan para las mafias o funcionarios corruptos, u oportunistas que tomaron provecho del conflicto para 'correr sus cercas' o para 'comprar barato'"

Al respecto, los mismos Principios Pinherios, en sus numerales 17.2, 17.3 y 17.4, por un lado le ordenan a los Estados a que (i) no se menoscaben los derechos de propietarios legítimos o de otros titulares de derecho a volver a tomar posesión de las viviendas, de las tierras o del patrimonio, (ii) a adoptar medidas positivas para proteger a aquellos que no dispongan de medios para acceder a otra vivienda adecuada cuando deben abandonar la que ocupan en ese momento, con el fin de que no se queden sin hogar, así como, a (iii) considerar la posibilidad de establecer mecanismos para indemnizar a los compradores que resulten perjudicados con la orden de restitución; por el otro, excluye expresamente la formación de derechos de buena fe sobre la propiedad cuando la gravedad del desplazamiento que originó el abandono de los bienes entrañe una notificación implícita de la ilegalidad de su adquisición.

Lo expuesto permite aproximarnos a la distinción de la ocupación secundaria frente a la figura de la oposición planteada en el artículo 88 de la Ley de Restitución y Formalización de Tierras, en los siguientes términos:

Los ocupantes secundarios se refieren a la categoría sustancial, reconocida en los Principios Pinherios, normatividad de la que se deriva el reconocimiento de tal población como un hecho social, y como un fenómeno que emerge de la problemática suscitada con el desplazamiento forzado producto de contexto de conflicto armado interno. Estos sujetos como afectados con la orden dispuesta en la sentencia favorable a la víctima, son inspiradores del estándar de interpretación de la política de restitución y formalización de tierras implementada en país.

Se trata pues de todas las personas que se vinculan a las tierras o predios abandonados como consecuencia de las migraciones forzadas, dentro de los cuales se hace indispensable distinguir a quienes en virtud de sus condiciones personales y de la forma en la que se establecieron o relacionaron con el fundo restituido, le asiste el derecho a hacerse beneficiarios de medidas compensatorias y/o indemnizatorias previstas en la Ley 1448 de 2011, de quienes por el contrario, en virtud de su proceder, quedan excluidos de tal reconocimiento. 
Otro factor que operó en contra de los movimientos y organizaciones sociales fue la agudización de la guerra, puesto que limitó las posibilidades para la organización social, la movilización e incluso para la creación de discursos e identidades políticas más allá de la confrontación amigoenemigo. (Cruz, 2016. p. 56)

Por su parte, la H. Corte Constitucional señaló de manera puntual en sentencia C - 330 de 2016 que el opositor se trata de una categoría procesal incorporada a la Ley de Víctimas, precisando que, la calificación del principio de buena fe a través del parámetro de ser exenta de culpa constituye un elemento sustancial al diseño institucional de la justicia restitutiva, puesto que además de propender por la protección de los derechos fundamentales de las víctimas, conduce al desmantelamiento de las estructuras ilegítimas que se articularon en el marco del conflicto armado para reproducir el despojo y luchar contra éste; de forma que teleológicamente es el resultado del profundo y detallado entendimiento de los hechos que caracterizaron los círculos de violencia por la tierra; justificación que para el máximo Tribunal Constitucional, conforme la interpretación dada sobre la materia, entraña un alto valor jurídico, demandando de todos los operadores judiciales, mantener y blindar aquél estándar probatorio en aras de evitar una legalización basada en tres factores inadmisibles constitucionalmente: El aprovechamiento abusivo de las condiciones de violencia que viciaron el consentimiento jurídico de las víctimas; la corrupción, que puso parte de la institucionalidad al servicio de los despojadores; y el formalismo del derecho, que favoreció a la parte más poderosa en el ámbito administrativo y judicial (Sentencia C - 330 de 2016, T - 315 de 2016, T - 529 de 2016, entre otras).

De esta forma, mientras que la oposición es una herramienta procesal instituida para controvertir el derecho de acción a la restitución de tierras; la ocupación secundaria es el fenómeno o hecho ocasionado con la relación material o jurídica que se afecta con la prosperidad de la pretensión incoada.

Resulta conveniente precisar que el hecho que un segundo ocupante no se presente como opositor al proceso, no releva al Juez de examinar la necesidad del reconocimiento de medidas de asistencia y atención que permitan protegerlo de la indigencia, así como de desalojos injustificados $u$ otras posibles violaciones de derechos humanos que exacerben las divisiones económicas, étnicas, sociales, y que en últimas se constituyan en nuevas rupturas de tejidos comunitarios generadores de conflictividades, a partir de la construcción de la relación consecuencial de segundo ocupante - predio restituido - necesidades insatisfechas, las cuales en ningún caso deben extenderse o transmutarse al referido estudio de procedencia de compensación económica, tal y como quedó consignado en el Auto de Seguimiento 373 de 2016. Para ello en particular, la Unidad Administrativa Especial de Restitución y Formalización de Tierras Despojadas y Abandonadas Forzosamente ha expedido distintos acuerdos que así lo disponen, el 
más reciente de ellos el Acuerdo No. 033 de 2016; sin embargo, este asunto no es el que ocupa el presente estudio.

Conduce el análisis esbozado a establecer que, los opositores como categoría procesal, no pueden ser sujetos de tipificaciones, categorizaciones o clasificaciones, pues ello resultarían enlistarlos al infinito, dado el carácter innominado de las excepciones de mérito que pueden proponerse en ataque a la pretensión; empero, lo que sí resulta transcendental para asegurar la igualdad en las decisiones judiciales, así como, la equidad en la distribución, acceso y uso de la tierra, protección a los derechos a vivienda digna, al trabajo agrario de subsistencia y el mínimo vital de quienes concurren al trámite, y con ello, la materialización del fin del proceso, es la determinación del estándar o parámetro de análisis de la conducta de quien se presente con el interés de demandar del Estado el reconocimiento de una compensación económica, para lo cual resulta indispensable la precisión de criterios de aplicación diferencial, pero más que ello de una herramienta metodológica de interpretación que permita justificar la decisión judicial que al respecto se adopte. Siendo este el camino para la consecución de la paz duradera y sostenible, a través de la reconciliación nacional, erradicando la posibilidad del florecimiento de nuevas problemáticas sociales producto de tratos discriminatorios.

\section{Criterios orientadores o reglas hermenéuticas para el análisis diferenciado la conducta de los sujetos afectados con la orden de restitución y formalización de tierras}

La Ley 1448 de 2011 señaló como único parámetro de análisis de la conducta del que, siendo afectado con la orden de restitución, persigue el reconocimiento de una compensación económica, la buena fe exenta de culpa, la cual ha de verificarse respecto del momento en que la persona establece su relación (jurídica o material) con el predio objeto de solicitud ( $\mathrm{H}$. Corte Constitucional, Sentencia C - 330 de 2016).

Sin embargo, ante la heterogeneidad de los segundos ocupantes, se demandó la constitucionalidad de la expresión exenta de culpa, teniendo como fundamento base el carácter demasiado estricto de tal estándar frente a una población igualmente vulnerable afectada con la orden de restitución. El Máximo Tribunal Constitucional, resuelve en sentencia de exequibilidad condicionada, estableciendo ciertos parámetros de aplicación diferencial, que conducen a la flexibilización o inaplicación de forma excepcional del estándar, que atienden a las condiciones personales del interesado al momento de llegar al predio, marcados por circunstancias constitutivas de debilidad manifiesta en lo que tiene que ver con el acceso a la tierra, la vivienda digna o el trabajo agrario de subsistencia y con la pregunta acerca de cuál es el nivel de diligencia con el que debió actuar, citándose a manera de ejemplo, la posibilidad de analizar su conducta bajo el faro de la buena fe simple, estado de necesidad, e incluso una concepción amplia (transicional) de la buena fe calificada. 
Enfatizó el Máximo Tribunal Constitucional que la exigencia del estándar de la buena fe calificada resulta una carga desproporcionada o inequitativa respecto de los segundos ocupantes en estado de vulnerabilidad, en relación a los cuales se acepta que la Ley de Víctimas guardó silencio; por lo que se acusa de tratar una problemática de discriminación indirecta que ha de superarse a través de la aplicación diferencial del referido parámetro, para lo cual la jurisprudencia dictada fijó unos criterios orientadores o reglas hermenéuticas que, para efectos de la presente investigación, se sintetizan así:

(i) Debe favorecer a personas que ostentan una relación fáctica o jurídica con el predio restituido.

(ii) Debe favorecer a personas que enfrentan condiciones de vulnerabilidad en el acceso a la tierra en procura, sin ánimo de exhaustividad, de proteger el principio de igualdad material, los derechos fundamentales a la vivienda digna y mínimo vital, trabajo, así como propiedad rural y fomento del agro (artículos 64 y $64 \mathrm{CP}$ ). Las personas que enfrentan ninguna condición de vulnerabilidad no deben ser eximidos del requisito.

(iii) No puede favorecer a personas que tuvieron una relación directa o indirecta con el despojo o el abandono forzoso del predio; ni tampoco a quien obró con pretensión de legitimarlo (armado o pretendidamente legal). Para ello, debe examinarse los contextos, precios irrisorios, violación de normas de acumulación de tierras, o incluso, la propia extensión de los predios, para determinar el estándar que resulte razonable.

(iv) Debe considerarse la situación de hecho del opositor/segundo ocupante en términos de conocimiento de derecho y economía.

(v) El reconocimiento de una compensación debe tener por finalidad la equidad social; debiéndose examinar la procedencia de una medida distinta a la del artículo 98 de la Ley 1448 de 2011.

(vi) Debe analizarse la procedencia de la remisión de los segundos ocupantes/opositores a programas de atención a población vulnerable por razones económicas, desplazamiento forzado, edad, o cualquier otra.

\section{Herramienta metodológica de interpretación para la aplicación diferencial del estándar de la buena fe exenta de culpa}

La disposición jurídica contenida en el artículo 98 de la Ley 1448 de 2011 que consagra como presupuesto del reconocimiento de una compensación económica en favor del afectado con la orden de restitución, la probanza de que su conducta se ajusta al estándar de la buena fe exenta de culpa, fue prevista por el legislador en la estructura tradicional de regla, como enunciado que consta de un supuesto de hecho y una consecuencia jurídica.

El citado estándar de la buena fe exenta de culpa, se fundamenta en el principio de rango constitucional previsto en el artículo 83 de la Carta Política, el cual se cualificó de esa forma, en 
aras de asegurar los fines del proceso, tales como desmantelamiento de las estructuras ilegítimas que se articularon en el marco del conflicto armado para reproducir el despojo, así como la develación y castigo del aprovechamiento abusivo de las condiciones de violencia que viciaron el consentimiento jurídico de las víctimas; de la corrupción, que puso parte de la institucionalidad al servicio de los despojadores; y el formalismo del derecho, que favoreció a la parte más poderosa en el ámbito administrativo y judicial (Sentencia C - 330 de 2016, T - 315 de 2016, T 529 de 2016, entre otras).

No obstante lo anterior, el máximo Tribunal Constitucional, al estudiar la exequibilidad de la expresión exenta de culpa, condicionó su constitucionalidad a la aplicación diferencial de tal estándar, fijando para ello unos criterios orientadores o reglas hermenéuticas en relación a las cuales, el operador judicial debe determinar cuándo debe aplicar el estándar general fijado en la Ley 1448 de 2011 de forma amplia, flexibilizarlo, morigerarlo o incluso inaplicarlo, en aras de atemperarse con la realidad social (Sentencia C - 330 de 2016 y Auto de Seguimiento 373 de 2016); y es precisamente en tal aplicación diferencial donde surge la necesidad que exista una fundamentación racional de la decisión, a través de una herramienta metodológica hermenéutica que permita así justificarlo.

De este modo, en atención a que justificación racional de la sentencia, yace en su motivación, se requiere un intenso ejercicio argumentativo para resolver la aplicación diferencial de la disposición en cita, pues no basta con hacer uso de los antes referidos criterios o reglas hermenéuticas para justificar la inaplicación o flexibilización del estándar, pues éstos lo único que previenen es la existencia de una colisión de los principios constitucionales, a saber: Por un lado, el principio de buena fe cualificado a través de la exigencia de ser exenta de culpa, a través del cual se pretende asegurar los principios de verdad, que propende por el desmantelamiento de dinámicas y estructuras de despojo y el de seguridad jurídica de las instituciones permeadas y afectadas por el estado de cosas inconstitucionales que propició el desplazamiento forzoso producto del conflicto armado; $y$, por el otro, los derechos a la igualdad material, equidad en la distribución, uso, acceso preferente y progresivo de la tierra, así como a la vivienda digna, debido proceso, trabajo, mínimo vital, entre otros derechos, de los segundos ocupantes vulnerables y afectados con la orden de desalojo que provoca la restitución.

Es allí donde surge la importancia de la hermenéutica y argumentación del operador judicial en cuanto al análisis de tal colisión, surgida con la posibilidad que, la buena fe exenta de culpa planteada inicialmente por el legislador como regla, se elevará por interpretación constitucional a la categoría de principio; pues, mientras que lo dispuesto en el artículo 98 de la Ley 1448 de 2011 se formuló en la estructura del todo o nada, la sentencia de constitucionalidad estableció que dicha disposición quedó supeditada a un estudio diferencial cuyo cumplimiento puede 
ocasionarse en diversos grados, según las posibilidades fácticas y jurídicas evidenciadas en el caso en concreto.

En tal sentido se ha precisarse que, mientras las reglas contienen mandatos definitivos y pueden ser cumplidas o no cumplidas, los principios no exigen un cumplimiento pleno de lo que ordenan, pueden ser cumplidos de manera gradual; tal distinción conduce a que en el proceso de justificación de la decisión en las antinomias entre reglas se apele a criterios tradicionales de jerarquía, temporalidad, especialidad, entre otros para proveer una solución, mientras que, cuando se está ante una contradicción normativa "en concreto", "externa" o propia del "discurso de aplicación", como las que se producen mayormente entre principios, se resuelve apelando a la ponderación, a partir de la cual se justifica objetivamente que, uno de los dos principios cede frente al otro, o en otros términos, el que tiene menos peso es desplazado por el que tiene más y no por ello se declara inválido el principio desplazado (Carrillo, 2013).

Al respecto de ello, si bien se distingue entre la justificación de las declaraciones normativas y la justificación de las decisiones jurídicas; entendidas las primeras como un discurso práctico y las segundas un discurso jurídico; siendo éste último en el que se fundamenta el reconocimiento de medidas compensatorias a ocupantes secundarios legítimos y vulnerables, para lo cual se previó por el Máximo Tribunal Constitucional un análisis y ejercicio argumentativo que tiene que hacer el Juez conforme las circunstancias y particularidades del caso concreto, para ALEXY, R. el ejercicio de racionalidad que se ejerce en el discurso jurídico se constituye para un caso particular del discurso práctico general, que se cimienta en la calidad de los procedimientos que se siguen en el proceso de justificación de la aplicación de los contenidos normativos (Feteris, 2007, pág. 151). En la justificación de las decisiones jurídicas, ALEXY, R. distingue dos niveles, la justificación interna y la justificación externa; la primera encaminada a establecer si la decisión se deduce lógicamente de las premisas que se aducen para justificarla, esto es un análisis lógico-deductivo al interior del silogismo; mientras que el objetivo de la segunda es mostrar la aceptabilidad de las premisas, ésta última se vale de la argumentación jurídica en casos, por ejemplo, en los que la norma permite más de una interpretación, requiriéndose justificar en la premisa mayor la interpretación elegida para ser aplicada; siendo éste el nivel en que cumple un papel, la exactitud material de las afirmaciones (Feteris, 2007).

De esta forma, el asunto relativo a la aplicación diferencial de la disposición del artículo 98 de la Ley 1448 de 2011, en cuanto a la exigencia de la probanza de una buena fe cualificada o exenta de culpa, merece un ejercicio de justificación externa en el que se expongan las razones objetivas que conducen a la elección de la interpretación de que tal disposición se adopta.

Frente a la aplicación de la disposición en cita, conforme viene expuesto, la Corte Constitucional 
al estudiarla, resolvió la exequibilidad condicionada, sujetándola a la interpretación que el operador judicial haga de ésta en el caso en concreto, basado en los criterios de orientación que vienen enlistados, respecto de los sujetos frente a quienes las circunstancias o condiciones personales al momento de llegar al predio, permiten predicar de éste vulnerabilidad en el acceso a la tierra o producto de afectaciones a sus derechos a igualdad material, vivienda digna, mínimo vital, trabajo, propiedad rural y fomento del agro (artículos 64 y 64 CP), tales criterios no son suficientes para estimarse por sí solos como unas subreglas constitucionales de inaplicación o flexibilización de la buena fe exenta de culpa requerida para acceder a una compensación, que permita resolver la cuestión a partir de un mero ejercicio de subsunción, sino más bien constituyen apenas criterios evaluativos de sospecha de discriminación indirecta que permite alertar al juez sobre la necesidad de realizar un examen de buena fe calificada a través de una herramienta metodología de interpretación que conduzca a resolver la colisión que viene descrita en párrafos precedentes, la cual no es otra que ponderación, que resulta principal e indispensable en el proceso de justificación externa de la interpretación que se adopta de la disposición jurídica - artículo 98 de la Ley 1448 de 2011.

Realizando entonces una aproximación al principio que teóricamente fundamenta la buena fe exenta de culpa, se hace necesario precisar que por la finalidad que persigue su cualificación o estrictez en el marco de la justicia transicional, éste depende del sujeto que bajo aquel se ampare. En el caso de la víctima, en el derecho a la libertad afectado por la coacción, constreñimiento que ocasionó el conflicto armado interno. Y, en el caso del Estado, en la seguridad jurídica carente en escenarios tempo-espaciales de institucionalidad, situación que se encuentra reconocida con la declaratoria de estado cosas inconstitucionales, ocasionada con fenómeno de desplazamiento masivo producto de la referida anormalidad del orden público (Sentencia T - 025 de 2004).

Es así como el principio de la buena fe exenta de culpa entra en colisión con los que vienen enlistados como amenazados de ser lesionados con la orden de restitución, para quienes se itera, adquieren por las particularidades de su vinculación, la calidad de ocupantes secundarios legítimos y vulnerables.

La extracción del operador deóntico de uno y otro extremo, con base en los principios enunciados, conduce por un lado a la prohibición de adquirir, ocupar o poseer predios ubicados en zonas afectadas por contextos de violencia generados por el conflicto interno armado, donde se ocasionaron fenómenos de desplazamiento, en aras de evitar una legalización basada en los tres factores inadmisibles constitucionalmente señalados en la Sentencia C - 330 de 2016, cuales son el aprovechamiento abusivo de las condiciones de violencia que viciaron el consentimiento jurídico de las víctimas, la corrupción que puso parte de la institucionalidad al servicio de los despojadores y el formalismo del derecho, que favoreció a la parte más poderosa en el ámbito 
administrativo y judicial. Mientras que, por el otro lado, el operador deóntico lo constituye la permisión de que tales transacciones o relaciones materiales se consoliden en tal contexto, producto de situaciones de vulnerabilidad socio-económica ocasionadas por derechos o mínimos prestacionales insatisfechos.

Ante tal planteamiento, la aplicación del test de ponderación, resulta ser la herramienta idónea de justificación de la decisión constitucional en materia de colisión de los principios antes referidos, pues su estructura metodológica, producto de un ejercicio que le imprime razonabilidad a la decisión; entiendo que, en asuntos como los que se desatan en el proceso de restitución y formalización de tierras, dada su naturaleza constitucional, la decisión jurídicamente correcta constituye respuestas a cuestiones prácticas, respecto de las cuales existen un sinnúmero de razones para resolverlas, las que judicialmente deberán ser analizadas respecto del caso particular que se decide, a fin de responder al ideal de justicia, como corrección respecto a la distribución y equilibrio que se alcance con la sentencia. Para lo expuesto se requiere de un método objetivo y controlable que no permita que la elección del principio que cede frente al otro, sea un acto de mera subjetividad de operador jurídico.

Pensemos entonces en un ejemplo en que se realice una ponderación relativa a las circunstancias del caso en concreto, planteado así: Tenemos por un lado a una persona respecto de quien se encuentran comprobadas las premisas fácticas para ser reconocida víctima del conflicto armado y proceder la restitución de un predio que abandonó forzosamente; $y$, en el otro extremo, un sujeto a quien, la orden de desalojo que dispone la sentencia, conduce a una lesión de sus derechos a la vivienda digna y la subsistencia mínima, que por las circunstancias bajo las cuales se ocasionó la negociación, podría predicarse un abierto desconocimiento de la normatividad civil y agraria, hecho constitutivo de una extrema imprudencia y negligencia, pues compró a través de una carta - venta, a bajo precio y con conocimiento del estado de anormalidad del orden público, respecto del cual éste mismo se informa como resiliente. Se precisa que no existe evidencia que permita vincular a este comprador con los actos de abandono forzoso y/o despojo.

Lo anterior conduce a que se genere una tensión entre el principio de buena fe estandarizado con la exigencia de ser exenta de culpa, que encuentra en el caso su fundamento teórico en la seguridad jurídica llevada a la institución de compraventa de bienes inmueble, en virtud de las negociaciones surgidas en el contextos de conflicto armado interno, pretendiéndose proscribir los tres factores inadmisibles que inspiran tal institución o parámetro; y por el otro, el principio de la dignidad humana de un sujeto igualmente en estado de vulnerabilidad determinado por sus condiciones socio económicas.

En tal caso, deberá determinarse el peso en concreto respecto del principio de dignidad humana 
en relación al principio de seguridad jurídica en cuanto al nivel de satisfacción y correlativa afectación de cada uno de ellos; para a continuación establecer su peso en abstracto de acuerdo a la importancia que éstos merecen en cuanto a los valores imperante en la sociedad; y finalmente determinar si, el operador deóntico impacta tal o cual principio, lo que ha de establecerse a través de la seguridad de las premisas empíricas. De extraerse de tal ejercicio de razonabilidad un nivel de satisfacción o afectación en igual proporción corresponderá al operador judicial acudir a la carga de la argumentación a través de sus reglas para su solución.

Conlleva lo expuesto, a que los criterios orientadores fijados por la jurisprudencia, sirvan conforme se ha expuesto, para advertir o alertar al juzgador cuando se encuentre frente a un asunto o situación constitucionalmente problemática, que amerita un análisis diferencial; más no la forma o guía metodología que resulta más eficaz al operador judicial para garantizar los derechos de los ocupantes secundarios legítimos y vulnerables, en aras de bridarles un tratamiento proporcional a su proceder y a sus condiciones personales, que además responda al diseño institucional de la política transicional diseñada para la restitución de tierras; lo cual se alcanza a partir del modelo de ponderación que resuelva tensión de principios constitucionalmente válidos.

\section{CONCLUSIÓN}

El análisis jurídico resultado de la presente investigación, permite arribar a las siguientes conclusiones:

La oposición constituye la herramienta procesal instituida por la Ley 1448 de 2011 para controvertir el derecho de acción a la restitución de tierras; mientras que la ocupación secundaria es el fenómeno o hecho ocasionado con la relación material o jurídica que se afecta con la prosperidad de la pretensión incoada. Esta última figura ha de examinarse como una categoría sustancial de la política institucional, cuya población objetivo se caracteriza por su heterogeneidad; de ahí que resulte indispensable analizar tanto las condiciones personales de cada sujeto que la aduce, como las circunstancias bajo las cuales se consolidó la referida vinculación con el inmueble pretendido, a fin de determinar su legitimidad en cuanto al acceso a medidas compensatorias y/o de asistencia o atención.

La estandarización del principio constitucional de buena fe, en cuanto requiere un análisis para ser catalogada como exenta de culpa, implica un presupuesto de procedencia de compensación económica en favor del opositor afectado con la orden de restitución, constituyéndose como un parámetro de probidad y una carga sustantiva al diseño institucional de la justicia restitutiva, que conforme la interpretación judicial, tiene como fundamento la proscripción del aprovechamiento abusivo de las condiciones de violencia que viciaron el consentimiento jurídico de las víctimas: la 
corrupción, que puso parte de la institucionalidad al servicio de los despojadores; y el formalismo del derecho, que favoreció a la parte más poderosa en el ámbito administrativo y judicial (Sentencia C - 330 de 2016, T - 315 de 2016, T - 529 de 2016, entre otras).

Al margen de lo anterior, las circunstancias de cada caso en particular, en cuanto al momento en que se consolidó la relación material y jurídica del segundo ocupante con el predio, constituye el punto de partida para determinar el análisis diferenciado del estándar de cualificación del principio de buena fe, a partir de la prevención de criterios evaluativos de sospecha de discriminación indirecta que alerten al juez sobre la colisión de principios, cuya tensión requiere el uso de una herramienta metodológica que permita justificar la decisión que se adopte.

En el escenario de la justificación de las decisiones jurídicas, el procedimiento que ha de seguirse, transciende del mero del ejercicio lógico-deductivo al interior del silogismo; requiere, además, la aplicación del test de ponderación, que proporciona un método objetivo y controlable que permite fundamentar la elección del principio que cede frente al otro, justificando no sólo la interpretación que de la disposición se hace sino la respuesta judicial a la que se arriba.

\section{REFERENCIAS BIBLIOGRÁFICAS}

CARRILLO, Y. (2013). Problemas ineludibles en la caracterización de los conflictos constitucionales y la ponderación de principios (Planteamiento de la cuestión). Saber, ciencia y libertad, 25-32.

CRUZ, E. (2016). El ciclo de protesta 2010-2016 en Colombia. Una explicación. Jurídicas CUC, 12(1), 31-62. DOI: http://dx.doi.org/10.17981/juridcuc.12.1.2016.3

FETERIS, E. (2007). Fundamentos de la argumentación jurídica: Revisión de las teorías sobre la justificación de las decisiones judiciales. Bogotá: Universidad Externado de Colombia.

QUINCHE, M., Peña, R., Parada, M., Ruíz, L., \& Álvarez, R. (2015). El amparo de Tierras: La acción, el proceso y el juez de restitución. Bogotá D. C.

RAMíREZ, Ó. (2013). Tipologías de opositores y terceros indentificados por la judicatura en el desarrollo del proceso de restitución de tierras. Conversatorios sobre restitución de tierras y territorios, encuentros regionales de intercambio de experiencias, diálogos de saberes y gestión de conocimiento., 71.

VARGAS, F. (2013). Actuales dilemas de la oposición, intervinientes y opositores vulnerables. "Conversatorios sobre restitución de tierras y territorios, encuentros regionales de intercambio de experiencias, diálogos de saberes y gestión de conocimiento, 83-84. 
NACIONES UNIDAS, Consejo Económico y Social, Comisión de Derechos Humanos, Subcomisión de Promoción y Protección de los Derechos Humanos. (2003). Informe preliminar del Relator Especial, Sr. Paulo Sergio Pinherio sobre Restitución de vivienda y de patrimonio con motivo de regreso de los refugiados y desplazados internos.

BERNAL C. Alexy, R., Moreso, J., Prieto, L., Clérico, L., Villaverde, I., Sánchez, R., Lopera, G. \& Ávila, R. (2008). El principio de proporcionalidad y la interpretación constitucional. Quito: Miguel Carbonell, Ministerio de Justicia y Derechos Humanos.

AGENCIA PRESIDENCIAL PARA LA ACCIÓN SOCIAL Y LA COOPERACIÓN INTERNACIONAL. (2010). Notas sobre el derecho a la restitución y experiencias internacionales de restitución de bienes. Bogotá: Equipo de comunicaciones, proyecto protección de tierras y patrimonio de la población desplazada.

COMISIÓN DE SEGUIMIENTO A LA POLÍTICA PÚBLICA SOBRE DESPLAZAMIENTO FORZADO. (2012). El reto, garantizar la superación del ECl en el marco de la nueva ley de víctimas. Bogotá: Corcas editores S.A.

KALACH, G. (2016). Las comisiones de la verdad en Colombia (2016) Revista Jurídica Mario Alario D'Filippo. VIII, (16): 106-124. Recuperado de DOI: https://doi.org/10.32997/2256-2796- vol.8num.16-2016-1534

ESCUELA JUDICIAL RODRIGO LARA BONILLA. (2014). Desplazamiento forzado, víctimas y restitución de tierras. Bogotá: Opciones graficas editores Ltda.

MOLANO, A. (2013). Dignidad Campesina: Entre la realidad y la esperanza. Bogotá: Icono editorial LTDA.

NACIONES UNIDAS, Consejo Económico y Social, Comisión de Derechos Humanos, Subcomisión de Promoción y Protección de los Derechos Humanos. (2005). Informe definitivo del Relator Especial, Sr. Paulo Sergio Pinherio sobre Restitución de vivienda y de patrimonio con motivo de regreso de los refugiados y desplazados internos.

NALEPA, M. (2012). Los orígenes de las reclamaciones antagonistas de tierra en el Este de Europa Central - la restitución en especie como un problema de división equitativa. En P. Kalmanovitz \& M. Saffon (Edres). Justicia distributiva en sociedades de transición. Torkel opsahl Academic EPublisher y Peace Research Institute Oslo 
Key Sandy Caro Mejía

GUTIÉRREZ, J. (2014). Costos sociales de transacción de la Ley de Restitución de Tierras en Colombia: Un país sin Reforma Agraria. Jurídicas CUC, 10 (1), 157 - 196. 